\title{
BEATRIZ DE NAZARÉ (1200-1268) E OS SETE MODOS DO AMOR ${ }^{1}$ BEATRICE OF NAZARETH (1200-1268) AND THE SEVEN WAYS OF HOLY LOVE
}

\author{
Maria Simone Marinho NOGUEIRA ${ }^{2}$
}

\begin{abstract}
Resumo: A mística feminina medieval, desenvolvida entre os séculos XII e XV, fala, com propriedade, de um conhecimento íntimo de Deus, de uma união entre o humano e o divino que se funde numa só forma e que pode ser lido à luz do que Bataille chama de erotismo sagrado, onde se desenvolve a ideia de se pertencer a um todo, pois, o que está sempre em questão é a substituição do isolamento do ser, de sua descontinuidade, por um sentimento de continuidade profunda. Este sentimento, por sua vez, pode ser visto em Beatriz de Nazaré (monja cisterciense, nascida em Tirlemont, na Bélgica, em 1200), quando ela pensa e vive o divino na sua plenitude: sem limites, sem objeções, sem intermediários (sine medio), no que podemos chamar de uma ascese do desejo, apresentada ao longo do seu livro Os sete modos de amor. No percurso de sua obra, Beatriz se mostra como uma autêntica trovadora de Deus, como uma anunciadora do divino, cujas ideias ultrapassam, em muito, os simples limites da razão. Desta forma, neste texto, pretendemos apresentar a experiência do desejo em Beatriz de Nazaré como a experiência absoluta do Amor (Minne) que, por sua vez, exige um desnudamento absoluto da alma (amante) que busca Deus (Amor), constituindo-se todos os sete modos do percurso da alma numa verdadeira ascese do desejo, sem, entretanto, deixar de lado toda uma erótica do conhecimento, vista a partir das ideias do conhecimento de si e do conhecimento de Deus.
\end{abstract}

Palavras-Chave: Desejo. Amor. Conhecimento.

Astract: The Medieval Female Mysticism was developed between the XII and XIV Century, speaks with property about the God intimate knowledge: a union between the human and the divine merged in a mold unique. That can be read, according to Bataille, as sacred erotism, which express the idea of being part of the whole, since hat is in evidence always the descontinuity substituition of the being for a sentiment of deep continuity. This sentiment can be seen in Betriz of Nazareth (cisterciense nun, was born in Tirlemont, Belgium, 1200), when she thinks and live the plenitud divine: no limits, no objections, no intermediaries (sine medio), what we call ascesis of desire, thesis present throughout her book The Seven Manners of Love. Throughout her work, Beatriz is an authentic troubador of God, a proclaimer of divine, with concepts exceed the simple limits of reason. Therefore, in this paper, we intented to show the desire's experience in Beatrice of Nazareth as the absolute experience of the love (Minne). This experience demands an absolute annihilation of the soul (Lover) that seeks God (Love). Therewith, all the seven modes of the soul's journey being constituted in a true ascesis of desire, without however abandoning an erotic of the knowledge, observed from ideas of knowledge yourself and of God's knownledge.

Keywords: Desire. Love. Knowledge.

\footnotetext{
${ }^{1}$ Este texto é fruto do projeto PIBIC/UEPB, Cota 2016-2017, intitulado: Por uma filosofia no feminino - Um resgate das mulheres na História da Filosofia. Também retoma, com alterações, o trabalho apresentado na PUC/Rio, no II Seminário Apophatiké de Estudos Interdisciplinares em Mística, em 2016 e a Conferência proferida no IV Encontro de Estudos Medievais na Paraíba/2017, A mística feminina medieval como um lugar para se perder, que se encontra nos Anais do Evento.

${ }^{2}$ Doutora em Filosofia pela Universidade de Coimbra. Professora Efetiva da Universidade Estadual da Paraíba, Professora Colaboradora da Pós-Graduação em Filosofia da UFPB. Coordenadora do Principium - Núcleo de Estudo e Pesquisa em Filosofia Medieval/UEPB. Pesquisadora do Apophatiké - Estudos Interdisciplinares em Mística/UFF.
} 


\section{Beatriz de Nazaré: vida e obra}

Beatriz de Nazaré nasceu na cidade de Tirlemont, na Bélgica, em 1200. Sexta fillha de uma família burguesa que acaba se tornando, sobretudo depois da morte da matriarca, uma "assombrosa família" do ponto de vista da formação de uma verdadeira comunidade religiosa ${ }^{3}$. A própria mãe de Beatriz lhe ensina os primeiros rudimentos escolares de forma que aos cinco anos ela já sabia o saltério decorado. Depois da morte da mãe, com sete anos de idade, o pai envia Beatriz para uma comunidade beguina onde começa a estudar as Artes Liberais (não chegando a terminar o trivium). Depois de algum tempo e a seu pedido, entra como oblata no mosteiro cisterciense de Florival e ali conclui os estudos do trivium e do quadrivium ${ }^{4}$.

Neste mesmo período inicia Beatriz uma vida de duras práticas ascéticas: deitar-se sobre espinhos, jejuar, usar vestidos incômodos, autoflagelar-se. Aos 15 anos deseja tornar-se noviça e, apesar do estupor da abadessa que não queria aceitá-la devido a sua debilitada condição física, termina por autorizar a sua entrada no convento no ano de 1215 . Um ano mais tarde faz sua profissão de fé e é enviada para o convento de Ramée, onde não só aprende o ofício de copista (o convento era famoso pelo trabalho das suas miniaturistas), como faz amizade com Ida de Nivelles (antes de ser uma cisterciense havia sido beguina) "[...] famosa por causa de seus progressos espirituais e experiências místicas. De sua mão, Beatriz se inicia na mistagogia e nos primeiros dias de janeiro de 1217 tem sua primeira experiência mística" (CIRLOT e GARÍ, 1999, p. 109)

Estes e outros dados da vida de Beatriz, como, por exemplo, das suas visões, podem ser encontrados na obra Vita Beatricis ${ }^{5}$, escrita em latim por um capelão anônimo que dispôs, segundo ele mesmo, das informações das monjas que conheceram a mística holandesa, assim como dos textos autobiográficos escritos pela própria Beatriz, em neerlandês, cujos originais misteriosamente se perderam, restando apenas a suposta tradução da Vita Beatricis ${ }^{6}$. Ao

\footnotetext{
${ }^{3}$ Como podemos depreender do texto que segue: "[...] la madre, Gertrudis, notable por su piedad y caridade; el padre, Bartolomé, después de la muerte de su mujer, acompanha a sus hijas Beatriz, Cristina y Sibila a los diferentes conventos que él mismo ayuada a fundar. Siguiendo con su hijo, converso con él, las observâncias cistercienses, se ocupaba de los assuntos externos de los monastérios de Florival, de Val des Vierges, cerca de Oplinter, em Brabante, y de Nazaret, cerca de Lierre. Otros dos de sus hijos entraron igualmente en órdenes religiosas" (ÉPINEY-BURGARD E BRUNN, 2007, p.122).

${ }^{4}$ As denominadas Artes Liberais na Idade Média, ensinadas nas Escolas e posteriormente nas Universidades, eram divididas em dois grupos: o trivium que compreendia a gramática, a retórica e a dialética; e o quadrivium, composto pelas disciplinas de aritmética, geometria, astronomia e música.

${ }^{5}$ As referências encontram-se no final do texto.

${ }^{6 “}$ En todo caso, el colorido latino del texto del capellán transforma con seguridade la voz de la priora neerlandesa, la simplifica, la adecua a los modelos institucionales de santidade feminina y la hace aceptable y comprensible para muchos. Apesar de ello, no necessariamente la enmudece. Detras de la hagiografia existe um personaje real, uma mujer que otras fuentes documentan como monja de los três conventos cistercienses y que además escrebió a ciencia certa cuanto menos un tratado sobre la experiência mística. Por ello, aunque la estrutura de la biografia
} 
contrário do que aconteceu com os escritos autobiográficos da nossa pensadora, foi conservado no original neerlandês seu tratado místico Seven manieren van minne (Os sete modos de amor), que até o início do século XX aparecia como anônimo e em 1925 foi restituído à sua autora, Beatriz de Nazaré, pelo jesuíta Leonce Reypens. A obra, embora tenha sido incluída no terceiro livro da Vita Beatricis ${ }^{7}$, nada apresenta de um discurso visionário. Como afirmam Épineyburgard e Brunn, se referindo aOs sete modos de amor: "Porém, não se trata de um relato cronológico, senão de uma síntese do que ela viveu: suas exaltações, inclusive seus excessos, encontram nesta obra uma expressão perfeitamente dominada no plano formal e no pensamento" (2007, p. 132-133). Passemos, então, ao texto em questão.

\section{Beatriz e Os sete modos de amor}

Em Os sete modos de amor, Beatriz de Nazaré reflete sua experiência do divino na sua plenitude: sem limites, sem objeções, sem intermediários (sine medio), no que podemos chamar de uma ascese do desejo, apresentada ao longo do seu livro. Seu texto, escrito em prosa rimada, em neerlandês médio, vai do mais puro refinamento da linguagem, passando por uma erótica do conhecimento até a mais apurada reflexão filosófica sobre as relações do humano com a dimensão do sagrado. No percurso apresentado, Beatriz se mostra como uma autêntica trovadora de Deus, como uma anunciadora do divino, cujas ideias ultrapassam, em muito, os simples limites da razão, sem cair, entretanto, na ideia de que diz coisas sem sentido.

No caminho de Os sete modos de amor fica-nos claro toda a formação letrada de Beatriz, desde as categorias encontradas no amor cortês (como a nobreza, a lealdade, a coragem, a ousadia, a consciência da distância), passando pela questão da liberdade tão cara ao movimento das beguinas, a filosofia dos cistercienses, tal como encontramos em Bernardo de Claraval e em Guilherme de Saint Thierry até as ideias neoplatônicas como a proodos e a

repite la de la Vita de Lutgarda de Tomás de Cantimpré y aunque las prácticas ascéticas del primer libro recuerdan com excessiva frecuencia y literalidade la Vita del Hermano lego de Villers, Arnulfo, al mismo tempo otros passajes, especialmente los capítulos doctrinales del segundo y tercer libro, revelan la autoria de Beatriz y su talento de maestra" (CIRLOT e GARÍ, 1999, p. 114-115). As informações iniciais de que não se trata apenas de uma tradução do neerlandês para o latim, como afirma o capelão tradutor do texto de Beatriz, encontram-se também em Kurt Ruh, 2002, p. 145.

7 "El capellán de Nazaret utiliza el tratado, como utiliza sus otros textos, para componer su obra y lo traduce al final del tercer libro integrándolo en la vida de la santa y transformando algunos aspectos fundamentales de su contenido. La comparación de ambas versiones, la neerlandesa y la latina, nos oferece así uma posibilidad insólita de constratar la escritura femenina y la elaboración que los hombres, sacerdotes y diretores espirituales, hicieron de ella” (CIRLOT e GARÍ, 1999, p. 113). 
epistrophè $e^{8}$ que cercam o núcleo de uma Minnemystik (mística do amor), onde desejo e abandono caminham juntos, pois, como afirma (TABUYO, 2004, p. 14): “[...] esta «mística do desejo» coincide com o que podemos denominar mística do abandono; não há contradição, desejo e abandono se correspondem na experiência radical da Minne-Amor, pois se trata de um desejo absoluto, e desejo de absoluto, que exige o desnudamento total". Neste sentido, experiência absoluta do Amor (Minne) exige, por sua vez, um desnudamento absoluto da alma (amante) que busca Deus (Amor), constituindo-se todos os sete modos do percurso da alma numa verdadeira ascese do desejo, sem, entretanto, deixar de lado toda uma erótica do conhecimento, vista a partir das ideias do conhecimento de si e do conhecimento de Deus.

Assim, Beatriz abre o seu tratado, como afirmam Toscano e Ancochea (cf., 2003, p.97), com uma profunda ressonância neoplatônica (seja pagã ou cristã) quando afirma: "Existem sete modos do santo Amor, que vêm do mais alto e ao mais alto retornam" (BEATRIZ DE NAZARÉ, 2004, p.35) ${ }^{9}$. No primeiro modo encontramos toda força do desejo relacionado à ideia do autoconhecimento. Desta forma, escreve nossa pensadora.

\begin{abstract}
O primeiro modo é um desejo ativo que surge do amor, que deve reinar muito tempo no coração antes de vencer todos os obstáculos; deve operar com força e vigilância e crescer audazmente enquanto dure esse estado. [...] A alma examina muitas vezes o que é e o que deve ser, o que tem e o que falta. Cheia de zelo e de ardente desejo, com toda a sagacidade do que é capaz, procura guardar-se e evitar tudo o que possa ser obstáculo às obras do amor. (BEATRIZ DE NAZARÉ, 2004, p.35 e 37, respectivamente).
\end{abstract}

Apesar da cisão que ocorre a partir do Século XII entre affectus (afeto) e intellectus (intelecto $)^{10}$, podemos perceber claramente já no primeiro modo de amor de Beatriz que desejo (ligado mais ao affectus) e reflexão (ligada mais ao intellectus) caminham juntos já que, apesar de o desejo ser ativo, operar com força, crescer audazmente, enfim, se caracterizar como um ardente desejo, isso não impede a mística holandesa de examinar com toda sagacidade do que é capaz. Desta forma, aquele que empreende o caminho do retorno se reconhece como ser desejante e pensante e, neste sentido, como afirmam Toscano e Ancochea (cf., 1998, p. 9), ser, amar e conhecer não podem ser conjugados como separados no que denominamos de mística especulativa e que inclui também a Minnemystik.

\footnotetext{
${ }^{8}$ Proodos e epistrophè, dois termos caros à terminologia neoplatônica, sobretudo a Plotino. Respectivamente, processão e retorno, ou seja, movimentos de saída da direção do Uno para a multiplicidade existente para além dele e de retorno à unidade desejada.

${ }^{9}$ A tradução de todas as citações da obra de Beatriz de Nazaré, bem como de todos os estudos citados é de nossa responsabilidade.

${ }^{10}$ Para o tema da cisão entre affectus e intellectus na Filosofia Medieval, veja-se nosso texto NOGUEIRA, 2013, p. 719-754.
} 
No segundo modo, apesar da sua curta extensão, se o comparamos com os outros modos, encontramos muitas ideias que influenciaram a mística de Beatriz como a literatura cortês, só que aqui invertida, posto que é a dama que quer servir gratuitamente ao seu senhor; a ideia do amor sem medida em relação a Deus, que encontramos no cisterciense Bernardo de Claraval (1090-1153) e ainda algo que, segundo os estudiosos, aparece pela primeira vez em Beatriz e em Hadewijch (?-1248) e que influenciará toda a tradição mística posterior, como Marguerite Porete (1260-1310), Mestre Eckhart (1260-1328) e, sobretudo, Angelus Silesius (1624-1677), com quem ganha a sua expressão mais poética: a ideia do sem porquê. Vejamos tudo que foi explicitado na escrita da própria Beatriz.

Outro modo de amor é quando a alma quer, às vezes, amar de forma completamente gratuita. Quer servir a nosso Senhor por nada, amar-lhe simplesmente, sem porquêe ${ }^{11}$, sem recompensa de graça ou de glória, como uma donzela que se entrega ao serviço de seu senhor por puro amor, sem salário algum, satisfeita de servir-lhe e de que ele se deixe servir.

Assim queria devolver fielmente amor ao Amor, servindo-lhe e amando-lhe sem medida $^{12}$, por cima de toda razão e de tudo quanto o homem possa pensar (BEATRIZ DE NAZARÉ, 2004, p.38 e 39).

Este amar sem medida e acima de toda razão dá a Beatriz, no terceiro modo, a real dimensão que separa a amante do Amado ou a criatura do criador. Ela afirma que o Bem desejado ultrapassa as forças humanas e supera o poder do próprio desejo, transformando esta busca irrealizável para qualquer criatura, por mais que esta lhe renda (ao Amor) graças, louvor, trabalho, sofrimento contínuo; e por isto neste modo, nossa mística diz que parece que morre sem morrer e que nesta morte sofre o inferno. Assim, a abertura do terceiro modo já acena para este cenário de esforço, penas e privações.

\footnotetext{
${ }^{11}$ Compare-se com a sentença de Silesius: "La rosa es sin porqué, florece porque florece, no se cuida de sí misma, no pregunta si se la ve" (ANGELUS SILESIUS, I, 289, 2000, p. 48). Veja-se o comentário em nota de rodapé do título da sentença: "Sin porqué: «Ohne warumb ». L.G.: «Un terminus technicus de la mística especulativa dominicana medieval, especialmente de Meister Eckhart. El sonder waeromme ya se halla antes por cierto en los escritos de la cisterciense Beatrij van Nazareth (muerta en 1268). Presumiblemente, traduce ésta con él el incomparable 〈Amo quia amo, amo ut amem〉(〈Amo porque amo, amo tan sólo para amar〉), acuñado en el comentario del Cantar de los Cantares por Bernhard von Clairvaux.... La fórmula se convirtió en una determinación fundamental de toda la mística del medioevo. »" (PLARD, 2000, p. 47-48).

${ }^{12}$ O capítulo I do De Diligendo Deo de Bernardo de Claraval tem como título uma pergunta: "Por que e em que modo Deus deve ser amado?" A pergunta se repete, numa outra formulação no início do capítulo e a resposta lembra muito o amando-lhe sem medida de Beatriz. Escreve Bernardo: "Vós quereis ouvir de mim por que e em que modo Deus há de ser amado? E eu vos respondo: a causa pela qual Deus há de ser amado é o próprio Deus; $o$ modo é amar sem modo" (BERNARDO DE CLARAVAL, 2010, p. 9, itálico nosso).
} 
No terceiro modo de amor a alma de boa vontade passa por grandes penas, pois quer a qualquer preço contentar o Amor, satisfazer-lhe em toda honra, em todo serviço, em total obediência e submissão de amor.

Às vezes o desejo se eleva violentamente na alma e ela se entrega com paixão, querendo fazer-lhe tudo. Não há virtude cuja perfeição não busque, não há nada que não queira sofrer ou suportar, nada que economize, nenhuma moderação admite em seu esforço. Está disposta a todos os desvelos, pronta e intrépida na pena e no esforço. Mas, faça o que faça, fica insatisfeita (BEATRIZ DE NAZARÉ, 2004, p. 39-40).

Esta insatisfação só cessará, em parte, quando, no finalzinho do terceiro modo, a alma passar do conhecimento de si ao conhecimento de Deus, quando só the resta permanecer naquele estado de martírio "até que nosso Senhor a console (a alma) em outro modo de amor, por um conhecimento mais íntimo. Então poderá exercitar o novo dom recebido" (Idem, p. 42 [parênteses nossos]). Neste conhecimento mais íntimo, o saber de si e o saber de Deus são as duas faces de um mesmo rosto iluminado pelo Amor que não exige reciprocidade porque a amante fundiu-se ao Amado, e o que parece uma simples obediência, na verdade, é intimidade, iluminação, gozo, liberdade, abismo de amor, como escreve Beatriz no quarto modo.

Às vezes parece que o amor se desperta docemente na alma, se levanta radiante $\mathrm{e}$ comove o coração sem ação alguma de natureza humana. O coração recebe então um toque delicado, é atraído tão vivamente por Amor, tão fortemente aprisionado, tão apaixonadamente enlaçado por ele, que a alma se rende, totalmente conquistada.

Experimenta uma intimidade nova com Deus, uma iluminação do espírito, um maravilhoso excesso de gozo, uma nobre liberdade e uma necessidade íntima de obedecer ao amor. Conhece então a plenitude e a superabundância. Sente que todas as suas faculdades pertencem ao Amor, que sua vontade é amor, se encontra submergida, abismada no amor, engolida por ele: ela mesma não é mais que amor (Idem, p. 43-44).

Essa plenitude e superabundância, portanto, esta saciedade encontrada no quarto modo difere do quinto, onde o corpo padece não de delícias, mas de sofrimentos e onde Cirlot e Garí chegam mesmo a denominar de uma perfeita coincidência dos opostos quando contrastam esses dois últimos estágios de amor e isso já aparece anunciado pela própria Beatriz no início do quarto grau quando ela escreve: "No quarto modo do amor nosso Senhor faz a alma apreciar ora grandes delícias ora grandes penas[...]” (BEATRIZ DE NAZARÉ, 2004, p. 43). Apreciar aqui tem o sentido valorativo, ou seja, de dar valor tanto às delícias quanto ao sofrimento. Assim, as delícias já foram valorizadas no quarto modo, agora, no quinto, entra em cena uma 
nova área semântica que nada deixa a desejar aOs quatro graus da violenta caridade de Ricardo de São Vítor (1110-1173) ${ }^{13}$. Vejamos como Beatriz abre seu quinto modo.

No quinto modo sucede às vezes que o amor se levanta na alma como uma tempestade, com grande fragor e furor, delicioso em excesso. O coração parece então romper-se e a alma sair de si mesma na experiência do amor e da fruição [...] (BEATRIZ DE NAZARÉ, 2004, p.45).

E mais adiante, continua.

Às vezes o amor transborda nela sem medida; brota com tal força, é seu toque tão furioso e abrasador que fere o coração por todas as partes. Dia a dia se renovam as feridas, cada vez mais dolorosas e ardentes. Parece-lhe também que as veias se rompem, que o sangue a abandona e a medula se consome. Desfalecem seus ossos, lhe explode o peito, a garganta seca. $\mathrm{O}$ rosto e todos seus membros experimentam a queimadura interior e a fúria soberana do amor. Às vezes é como uma flecha que lhe atravessa o coração até a garganta e mais além, até o cérebro, e a faz perder o sentido. Ou como um fogo devorador que atrai tudo o que pode consumir: tal é a violência que a alma experimenta, a ação nela do Amor (Idem, 47).

Como podemos perceber, todo o corpo de Beatriz fala. O desejo lhe consome completamente causado pela sua incapacidade de se satisfazer no Amor, parece que quanto mais incapaz de atingir a plenitude, mais esta tormenta ou fúria (orewoet) ${ }^{14}$ se apresenta como necessária, como os opostos que não se contradizem, mas se complementam e assim ela o diz no final do quinto modo:

Pois quanto mais recebe do alto, mais reclama, quanto mais se lhe revela, mais urge o desejo de aproximar-se dessa luz que é a verdade, a pureza, a nobreza e a fruição do Amor. E é assim seduzida, arrastada com mais força cada dia, nunca satisfeita nem apaziguada. O que mais a devora e a atormenta é o mesmo que a cura e a consola; o que a fere mais profundamente é o único que lhe proporciona a saúde (Idem, p. 49).

Os modos quarto e quinto, apesar de diferentes, aparecem como complementares já que se trata de "sofrer" tanto as delícias quanto as tormentas do Amor. No entanto, no sexto estado, nada dos altos e baixos dos modos anteriores são percebidos. O que aparece com muita transparência é um perfeito equilíbrio do ser (da alma/amante) que quer buscar a Deus/Amor. Assim inicia Beatriz seu sexto modo:

$\mathrm{Na}$ sexta maneira, quando a alma está mais elevada e avançada no caminho, experimenta, ainda, outro modo de amor com um conhecimento mais profundo. Sente

${ }^{13}$ Cf. RICHARD DE SAINT-VICTOR, 2006, p.155-156.

14 Orewoet, em neerlandês, (tormenta ou fúria de amor, em português), tema extremamente caro a sua contemporânea Hadewijch, tanto nas Cartas quanto nos Poemas. 
que o amor venceu suas faltas, domina seus sentidos, adorna sua natureza e a dilata e exalta seu ser (Idem, p. 50).

É interessante ver como neste modo há duas ideias principais, a do domínio de si e a da liberdade. Para tanto, utiliza três metáforas: a da dona de uma casa, a do peixe e a do pássaro. A metáfora da dona de casa representa a ideia do domínio de si, pois ela ordena tudo sabiamente como lhe convém, faz ou desfaz de acordo com a sua vontade, abre e fecha com capricho determinados cômodos, protege o que deve ser protegido, embeleza o que é digno de ser embelezado, enfim, assim também deve fazer com a sua alma. As metáforas do peixe e do pássaro valem para a liberdade e desta forma escreve Beatriz: "E como o peixe que nada na amplitude do rio ou descansa em sua profundidade, como o pássaro que voa audaz nas alturas, [...] assim ela sente que seu espírito vaga livremente na deliciosa abundância de Amor” (Idem, p.51).

Como já dissemos, o autodomínio e a liberdade se destacam neste sexto modo de amor, ao ponto de a nossa pensadora afirmar que é possível viver uma vida angélica neste mundo, atravessando todos os modos de amor e tendo o discernimento necessário para retirar de cada um deles o que eles têm para oferecer, desde o desejo que impulsiona todos os atos (do mais suave ao mais violento), passando pela gratuidade do Amor até o atrevimento de não temer nem homens, nem demônios, nem anjos, nem santos, nem mesmo Deus. Afinal, a conclusão do sétimo modo de Beatriz é: "Isto é a liberdade de consciência, doçura de coração, sabedoria dos sentidos, nobreza de alma, elevação do espírito e começo da vida eterna. É uma vida angélica neste mundo que em outra vida terá continuação" (Idem, p. 53).

Os estudiosos do texto de Beatriz tendem a dizer que Os setes modos de amor poderiam ser encerrados no sexto, não só pela superação da finitude que ali aparece (e que é uma das características da mística) como também pela forma como conclui este modo: "Que Deus nos conceda (a vida angélica neste mundo) a todos! Assim seja!”. No entanto, nossa pensadora apresenta-nos ainda um sétimo modo que continua trazendo problemas em termos de interpretação. Para uns, deveria vir antes do sexto; para outros, trata-se de um acréscimo feito no final da vida de Beatriz para resumir sua experiência; mas pode-se admitir também que se trata mesmo de um novo modo, o sétimo, que, como afirmam Épiney-Burgard e Brunn (cf., 2007 , p. 138), volta a passar por todos os estados anteriores, mas num outro nível, como se fosse uma espécie de espiral que levasse cada vez mais para o alto a experiência pela qual passou Beatriz. 
É fato que há todo um novo vocabulário neste sétimo modo e com este um novo espaço e um novo tempo. É como se Beatriz passasse do instante da vida angélica na terra para a promessa de uma vida de beatitude na eternidade. Passa-se, assim, de um tempo final para um tempo pleno $^{15}$; por isso a terra e tudo o que ela representa tonar-se um exílio do qual Beatriz busca libertar-se e, nesta busca, é como se todos os outros modos retornassem a título de reflexão da própria experiência do seu desejo ${ }^{16}$, pois A Amada não deixa de buscar o Amor. Para Beatriz, o sétimo modo é o do amor sublime, pois assim ela escreve:

\begin{abstract}
A alma bem-aventurada conhece ainda um sétimo modo de amor sublime que realiza nela interiormente um trabalho singular. É atraída no amor acima de si mesma, mais além dos sentidos, mais além da razão humana e de toda operação de seu próprio coração. É introduzida pelo Amor eterno na eternidade do amor, na imensidão incompreensível, na largura e na altura inacessíveis, no abismo sem fundo da Divindade, que está em tudo mais e mais além de tudo e permanece incognoscível, imutável na plenitude do ser que tudo pode, que tudo abarca e opera sempre com seu ato soberano (BEATRIZ DE NAZARÉ, 2004, p. 53-54).
\end{abstract}

Trata-se, realmente, de um tempo pleno, posto que a alma bem-aventurada é introduzida na eternidade pelo Amor, muito além da vontade e da razão. Supera-se, portanto, a suposta dicotomia das instâncias humanas (affectus e intellectus) e inaugura-se um novo tempo, não mais o angélico em vida, mas o eterno que tudo abarca no abismo sem fundo da Divindade.

\title{
Considerações finais
}

A título de conclusão, e retomando Os sete modos de amor de Beatriz de Nazaré, podemos dizer que o caminho apresentado pela pensadora holandesa nos oferece, para além da expressão da sua própria experiência do desejo de Deus, também uma profunda reflexão filosófica de que o desejo nos leva ao radical conhecimento de si e do divino. Nesta direção, toda uma erótica do conhecimento é construída, não só pela força que o corpo e os afetos exercem no seu texto, como também por toda influência da literatura cortês que ali se apresenta e, claro, porque toda esta linguagem erótica é uma característica marcante da mística feminina medieval ${ }^{17}$.

\footnotetext{
${ }^{15}$ As expressões são de ÉPINEY-BERGARD e BRUN, 2007, p. 139.

16 Daí nossa ideia de uma ascese do desejo que deve ser entendida, primeiramente, no sentido grego da palavra áskesis (exercício). E em Beatriz trata-se mesmo de um exercício (físico, moral e intelectual) em vista de um progresso espiritual. Assim parece entender também o "seu biógrafo" que divide a vida de beatriz em três fases que estão claramente em um plano de progresso espiritual: iniciação, progresso e perfeição.

${ }^{17}$ Veja-se o que escreve Lacan em um dos seus seminários quando entende a mística como um fenômeno bem peculiarmente feminino. Cf. LACAN, 1985, p. 87-104.
} 
Assim, quando avaliamos a experiência do desejo em Beatriz, percebemos que inicialmente o desejo aparece como uma atividade que tanto impulsiona a alma para Deus como requer que esta mesma alma realize um autoconhecimento. Depois o desejo busca devolver amor ao Amor numa atitude de gratuidade, sem porquê (segundo modo). Em contraste com esta gratuidade e porque parece ser próprio da natureza do desejo desejar, ele aparece como violento e não mede esforços para satisfazer sua sede de Deus, cai, assim, no abismo do Amor, onde oscila, nos dois modos seguintes (quarto e quinto), no toque suave das delícias às tempestades do amor. No sexto modo, enfim, a experiência do desejo encontra-se no domínio de si e, neste domínio, tem consciência da dignidade, da nobreza e da liberdade da alma. Estas ideias, por sua vez, são frutos do Amor, já que Beatriz compreende que somos da linhagem de Deus e, assim, tudo vem do Amor e a ele retorna. Desta forma, por mais afetivo que se mostre o texto de Beatriz, o que ela nos apresenta é uma experiência absoluta do Amor (Minne) que, como ela mesma nos diz no último modo, está além dos sentidos, da razão e do seu próprio coração (sendo, portanto, também conhecimento), sem, entretanto, deixar de abarcar absolutamente tudo na sua plenitude.

\section{Referências}

ARBLASTER, John \& FAESEN, Rob. "The influence of Beatrice of Nazareth on Marguerite Porete: The Seven Manners of Love Revised. In: Cîteaux: Commentarii Cistercienses. Revue d'Histoire Cistercienne,fasc. 1-2, 2013, p. 41-88.

https://irias.kuleuven.be/handle/123456789/412675 [Acesso em 10 de Set.2016].

BEATRIZ DE NAZARET. Los siete modos de amor. Vidas y visiones. Trad. María Tabuyo, Barcelona: José J. de Olañeta, 2004, p. 35-63.

BERNARDO DE CLARAVAL. De diligendo Deo. "Deus há de ser amado". Trad. Matteo Raschietti, Petrópolis: Vozes, 2010.

CIRLOT, Victoria e GARÍ, Blanca. La mirada interior. Escritoras místicas y visionarias en La edad media. Barcelona: Ediciones Martínez Roca, 1999.

ÉPINEY-BURGARD, G. e BRUNN, Émile Zum. Mujeres trovadoras de Dios - Uma tradición silenciada de la Europa medieval. Trad. de A. López e M. Tabuyo. Barcelona: Paidós, 2007.

GUILHERME DE SAINT-THIERRY. De natura et dignitate amoris. In: Amour plurielles. IMBACH, Ruedi e ATUCHA, Iñigo (Orgs.), Paris: Éditions du Seuil, 2006, p.32-49.

LACAN, Jacques. O Seminário: Livro 20, mais ainda. Trad. M. D. Magno. $2^{\mathrm{a}}$ ed., Rio de Janeiro: Jorge Zahar Editor, 1985. 
NOGUEIRA, Maria Simone Marinho. "Nicolau de Cusa e a Correspondência com os monges de Tegernsee". In.: Anais... XIII Congresso Internacional de Filosofia Medieval, Vitória, Espírito Santo, Agosto, 1-4, 2011/ Autor: Comissão Organizadora do XIII Congresso Internacional de Filosofia Medieval/ Organizado por Jorge Augusto da Silva Santos e Ricardo da Costa. Vitória: DLL/UFES, 2013, p. 719-754.

RICHARD DE SAINT-VICTOR. De quattuor gradibus violentiae caritatis. In: Amour plurielles. IMBACH, Ruedi e ATUCHA, Iñigo (Orgs.), Paris: Éditions du Seuil, 2006, p.144159.

RUH, Kurt. Storia della Mistica Occidentale. Mistica femminile e mistica francescana delle origini. Trad. de Giuliana Cavallo-Guzzo. Milano: Vita e Pensiero, 2002.

SILESIUS, Johannes Angelus. Peregrino Querubínico o rimas espirituales: gnómicas y epigramáticas que conducen a la divina contemplación. Trad. Héctor A. Piccoli. Argentina: Ediciones Nieva Hélade, 2000 (www.bibliele.com/silesius).

TOSCANO, María e ANCOCHEA, Germán. Mujeres em busca del amado. Catorce siglos de místicas cristianas. Barcelona: Ediciones Obelisco, 2003.

Recebido em 22/08/2017

Aceito para publicação em 25/10/2017 